\title{
Aesthetic Values in Chemistry
}

\section{Joachim Schummer}

js@hyle.org

\begin{abstract}
:
This paper investigates the role of aesthetic values in chemical research with regard to the sensual qualities of materials; microscopic structures with a particular focus on symmetry; molecular representations in supramolecular chemistry; chemical experimentation; and mathematical modeling in chemical engineering and physical chemistry. I argue that aesthetic values are important motivation and guidance in all these areas, although their relationship to epistemic and utilitarian values is mixed. They can both help open up entirely new research fields and make blind for new opportunities. Being aware of their existence and understanding their impact, chemists can better take advantage of them without falling victim to their possible misguidance.
\end{abstract}

\section{Keywords:}

Chemistry, aesthetics, sensual experience, symmetry, supramolecular chemistry, styles of experimentation, mathematical modeling.

\section{Introduction}

Following a famous statement by Marcelin Berthelot (1860, p. 811), chemists have frequently compared their work to that of art because, like artists and unlike other natural scientists, they create their own objects of study on a regular basis or are creative inventors in a similar sense as artists are (Jacobs 2006, ch. III.4-5). The more the public image of chemistry turned negative (Schummer et al. 2007), the more frequently did chemists allude to the artistic or aesthetic character of their work.

Philosophers of science have hardly taken such allusions seriously, partly for good reasons. On the one hand, the classical term "art" (or Latin ars), including Berthelot's French term art in the cited passage, usually designates technology or crafts rather than the fine arts, such that the comparison to "art" could easily undermine chemistry's status as a natural science. On the other, the forced associations with the fine arts, which typically lack philosophical substantiation, frequently appear as a desperate way of polishing the public image of chemistry, an all too obvious public relation effort. However, mainstream philosophers of science, who have almost exclusively focused on mathematical physics, have neglected not only anything related to chemistry but also any values in science other than epistemic values; thus, aesthetic values in science, similarly as ethical and technological values, are simply beyond their horizon. ${ }^{1}$

Unlike the image of science that mainstream philosophy has presented us, with its onesided focus on the search for the truth of theories, the experimental sciences like chemistry are a pluralistic endeavor (Schummer 2014). Apart from reliable models for explanation and prediction, chemists also work on the classification of substances and reactions, on synthetic and analytic capacities as well as on improving the world through understanding and technological changes. The pluralism of aims entails a pluralism of values, including not only epistemic values, such as predictive and explanatory values of models or the

1 Early non-mainstream exceptions, which all largely neglect chemistry, include Wechsler 1978; Curtin 1982; Tauber 1996; and particularly McAllister 1996. 
comprehensiveness and sharpness of classificatory concepts, but also ethical values embedded in ideas of a perfect world as well as instrumental or technological values, such as the usefulness, practicability and performance of tools and methods. Once we acknowledge the scientific pluralism of values, which are not governed by an over-arching value that some philosophers call TRUTH, but which rather spread out science into diverse branches and specialties and keep it alive through conflicts of values and personal preferences, it becomes reasonable to take the aesthetic allusions by chemists seriously and look for aesthetic values at work in chemical research.

Serious aesthetic studies of chemistry are still in an early state. ${ }^{2}$ It is not even easy to provide a clear and comprehensive definition of aesthetic values in science. On the one hand, that is due to an influential pre-modern tradition that has lumped together epistemic, ethical and aesthetic values (in Latin: verum, bonum et pulchrum), such that still today people use the term "beautiful" to praise the correctness or usefulness of results. On the other, the aesthetic dimension goes far beyond beauty and includes experiences of the ugly, irritating, and disturbing as well as of harmony and connectedness, and more broadly various kinds of general moods and attitudes towards oneself, one's work, and the world. For instance, a particular style of reasoning or experimentation, which is not required for methodological reasons but which clearly distinguishes a researcher, a group, or a school, could reveal the appreciation of certain aesthetic values.

A first-order approach to identify aesthetic values at work in chemistry, which will be used in the following, is to look for specific appreciations (and aversions) in the research process that are not primarily based on epistemic, instrumental, or ethical values. The identification by exclusion has the advantage of keeping aesthetic values apart from other value fields, in order to determine their mutual impact. Rather than making the blind and overstretched assumption that beauty would be a guide to truth, the following analysis aims at understanding if and how aesthetic values influence the chemical research process, both positively and negatively regarding epistemic and utilitarian values. By reviewing and drawing on various previous works, the analysis focuses on five aspects of chemical research in which aesthetic values have played a discernible role: materials (Sect. 2), microscopic structures with a particular focus on symmetry (Sect. 3), molecular representations (Sect. 4), chemical experimentation (Sect. 5), and mathematical modeling in chemical engineering and physical chemistry (Sect. 6).

\section{The aesthetic appeal of materials}

The Western tradition of aesthetics has long been dominated by very specific issues, such as theories of beauty and, particularly, art criticism, in which many have sought a profitable business. However, beyond that extremely narrow focus, the original meaning of aesthetics is much broader and goes back to Greek aisthesis, the knowledge of our sensations, particularly of how sensations induce emotions, attitudes, and judgments beyond epistemic and moral judgments proper. ${ }^{3}$ Paradigm cases of aesthetic phenomena are the sensation of an odor that makes people feel happy or sick; certain sounds, colors, tastes, or sensual environments that bring people into a certain mood, and so on. Since most of our sensations are based on, or directly refer to, sensual qualities of materials, materials should play a pivotal role in aesthetics.

2 For collections of essays, some of which are partly driven by popularization efforts, see Spector \& Schummer 2003; Fabbrizzi 2012; Spector 2013; Weibel and Fruk 2013.

3 This roughly corresponds to the concept of Alexander Baumgarten, who first introduced the term 'aesthetics' in his Aesthetica (1750-8) and partly also to ideas in Edmund Burke's A Philosophical Enquiry into the Origin of Our Ideas of the Sublime and Beautiful (1757). 
Chemistry, including the chemical crafts, has ever since made important contributions to aesthetically shaping our world. ${ }^{4}$ Two examples, the manufacturing of colors and plastics, may illustrate that and at the same time point to the cultural dimensions of its aesthetic involvement.

Throughout the history and prehistory of chemistry, color has played a pivotal role in human culture (Ball 2001). The use of natural pigments as body paints for ritual purposes is documented for as early as the Middle Stone Age, i.e. approximately 300,000 years ago (Barham 2002). Colored glass-like stones were fabricated both in Egypt and Mesopotamia before $4000 \mathrm{BC}$. The earliest synthetic pigment (blue ground frit, $\mathrm{CaO}-\mathrm{CuO}-4 \mathrm{SiO}_{4}$ ) was already manufactured about 2650 BC (Multhauf 1966, p. 19), and many should follow in the prehistoric period for uses in painting and cosmetics. Insofar as alchemy has its roots in Hellenistic Alexandria, it refers to the "coloring of metals", be it by surface treating or by alloying. The alchemical hierarchy of metals - with lead at the bottom, copper somewhere in the middle, and gold at the top - is grounded on an aesthetic hierarchy of colors (black, red, yellow), which is incidentally preserved in the German flag. The late 19th-century success story of the chemical industry was mainly based on the mass production of synthetic dyes, which chemists like William H. Perkin (1838-1907) had first made shortly before (Ihde 1964, p. 454 ff.). Their cheap and non-fade dyes rapidly spread all over the world and radically changed the visual environment in such way that it is fair to speak of an aesthetic revolution.

The second example of chemistry's large-scale impact on our aesthetic sensation of the world began with the mass production of plastics. ${ }^{5}$ Used as surrogates for natural materials like wood, metals, wool, and cotton, plastics soon became a symbol of modernism, or even futurism, the utopia of an entirely technologically supported form of life that is independent of "nature". There is probably no better example to illustrate the cultural aesthetics of materials, since the mere sensation of a piece of plastic, say polyethylene, may induce strong feelings. Those who subscribe to the futuristic utopia prefer plastics over natural materials regardless of their functionality, as they relate the material to their own ideas of life. In times and cultures where such ideas are prevailing, a synthetic imitation of a flower may be considered more beautiful than the original. For others, imitations are essentially inferior to their originals, regardless of practical usefulness. If people dislike surrogates simply because of their lack of naturalness and authenticity, their attitude is again based on aesthetic values. Thus, the material is considered either beautiful or ugly. There has been a long debate on the aesthetic preference of nature versus art, of the natural versus the synthetic and imitative since early antiquity. Knowingly or not the chemical community has taken a firm stand in that debate (Schummer 2003b).

It would be hard to deny that aesthetic values, particularly a sense of beauty and a fascination with the synthetic, have been driving forces for chemists researching colors, dyes, odors, flavors, plastics, "smart materials", and so on. Yet, apart from such applied research, also the visual and olfactory sensations of chemical substances in the laboratory, including the growth of crystals, change of colors, and the development of fumes, smells, and noises in the course of chemical reactions, have ever been aesthetically appealing to many people. From Faraday's famous experimental lectures for public audiences to chemistry kits, through which children could gain hands-on and sensual experience, the aesthetic appeal has also been widely used for the popularization of chemistry (Knight 2006). And many chemists later confessed that it had to a large extend been those sensual laboratory experiences which had made them decide for their profession (Root-Bernstein 2003). Although it is difficult to specify the specific aesthetic values at work here, it is likely a fascination with unusual, incomprehensible, surprising, perhaps even mysterious, phenomena along with curiosity and the pleasure of exploring the unknown.

$4 \quad$ On the following, see in more detail Schummer 1995 \& 2003a.

$5 \quad$ For the early history of plastics, see Glenz 1985 and Mossman 1997. 
For most working chemists the sensual laboratory experiences have tremendously changed since the mid-20th century because of radical changes in chemical instrumentation (Schummer 2002). First, thanks to high-resolution spectroscopy and the miniaturization of classical reaction vessels, chemical research can now be performed on extremely small samples to the point where the sensual experience of, say, a few micrograms vanishes. Second, since the 1950s, traditional methods for the characterization and identification of substances, from boiling and melting point analysis to chemical reaction tests, have been replaced by spectroscopic methods that reduce the physical interaction between researchers and their materials to a minimum. Third, since the 1970s classical purification techniques, such as distillation and recrystallization, have been ousted by chromatography with immediate follow-up spectroscopic analysis, such that a sensual experience of chemical reaction products is no longer required or even impossible. Nowadays one can produce and fully characterize new substances without having any sensual contact to the material. The changes in chemical instrumentation were so radical that they even induced an ontological shift: For most chemists outside of applied research the proper objects of their investigation are no longer chemical substances and their transformation, but molecular and interatomic structures and their reconfiguration, to which they have no sensual access. Instead, the visual representations of those structures, molecular graphs and three-dimensional models, have become their main objects of sense perception and aesthetic appreciation (Section $3 \& 4$ ). In so doing, chemists seem to subscribe to 19th-century idealistic aesthetics, which in any possible regard favored form over matter, the composition of forms and lines over the material quality of paintings and sculptures, or the structure of a narrative over its content.

Against that background, it is more than likely that the impact of material aesthetics on chemical research and on attracting young people to chemistry is rapidly dwindling. That might be different in applied research as well as in materials science, where the properties of materials still matter and where their theoretical representations are considered means to improve our understanding rather than the proper objects of investigation.

\section{The quest for symmetry}

From ancient Greece to the early 19th century, symmetry was a purely aesthetic concept to describe the balanced proportions, which were taken from the model of the perfect human figure, both between the parts of an artwork and between each part and the whole. ${ }^{6}$ For instance, Michelangelo's statue David embodies the ideal of aesthetic symmetry while lacking any element of mathematical symmetry in the modern sense. In contrast the modern concept of symmetry, which was developed only in mid-19th-century crystallography (Schummer 2006a), is a mathematical description of forms according to the invariance with regard to certain transformations, such as reflection on a mirror plane, rotation around an axis at a certain angle, or lateral translation by a certain length. In that approach, the higher the symmetry, the simpler is the form, which makes symmetry a measure of mathematical simplicity. Because of the influence of Plato, who in his dialogue Timaeus considered mathematical simplicity a measure of natural beauty, and because of the ambiguity of the term "symmetry", mathematical symmetry could turn into an aesthetic criterion in science. That is in sharp contrast to art and aesthetics, where mathematical symmetry is at best considered a framework for producing breaks and distortions, if not the epitome of the boring and monotonous (Schummer 2006a). Following Immanuel Kant's Critique of Judgement $(\S 22)$, one could argue that scientists value symmetry/simplicity because it pleases their epistemic rather than their aesthetic sense, as symmetrical forms are easy to comprehend. However, in as much as symmetry/simplicity is not an accepted epistemic criterion in the

6 Sections 3-6 of this paper draw on section 3, written by the author, of Schummer et al. 2009. 
experimental sciences, it describes an extra-epistemic value and an important heuristic research principle, and only as such it may be considered aesthetic.

Mathematical symmetry plays a fundamental role in chemistry to describe crystal structures and molecules, to identify forms of molecular isomerism, to develop quantumchemical models, to analyze spectroscopic results, and so on. There are even quantumchemical rules, the Woodward-Hoffman rules, for which Roald Hoffmann received the 1981 Nobel Prize in Chemistry, that predict the products of certain reactions from the symmetry of molecular orbitals. Apart from such routine uses, however, symmetry is also a guiding principle of research by suggesting certain explanations about the natural order of substances or certain synthetic strategies for the design of new products. In these contexts, symmetry functions as an aesthetic principle that can guide or misguide research from an epistemic point of view. Three examples may illustrate that.

One of the most flourishing fields of chemistry since the 20th century has been the synthesis and study of transition metal complexes. These compounds, which were long neglected because they belonged neither to organic nor to inorganic chemistry, have received particularly attention because of their potential use as catalysts in petrochemical processes and polymer production. In liquid solution their structure is rather instable, so that they are complexes rather than molecules, which made their structural analysis much more difficult. Synthesizing and studying hundreds of such compounds in the 1890s, Alfred Werner (18661919) brought order to the matter and thus established the entire field, for which he eventually received the Chemistry Nobel Prize in 1913. Since he found that other atoms combine with transition metals only at the numbers of $3,4,6$, and 8 , he suggested that these atoms are coordinated around the transition metals in a regular way. And because Werner, like Plato, believed that "nature" prefers simple and symmetrical structures, he suggested that complexes form regular polyhedra, for instance, that coordination number 6 corresponds to a regular octahedron. ${ }^{7}$ Werner's aesthetic intuition proved largely successful in later x-ray diffraction studies, but exceptions began to grow. In a theoretical study of 1937, Hermann A. Jahn (19071979) and Edward Teller (1908-2003) showed that in certain cases regular polyhedra are instable, such that the actual structures are distorted polyhedra. The result was a blow to all Platonist, because it suggested that "nature" sometimes prefers distortion over regularity. However, Werner's aesthetically driven choice has survived as a first-order approach to structural classification that distinguishes between regular structures as the norm and the distorted ones as exceptions.

While these distortions cannot be corrected by chemical means, there are many other examples where chemists have worked hard to produce the ideal, aesthetically preferred form. The most prominent and important one is the ideal crystal, which requires tremendous efforts at purification and recrystallization, without being ever achieved in practice because of remaining impurities and entropy effects. The ideal crystal has perfect translational symmetry such that a small unit represents the whole crystal, which allows for theoretical representation. In addition to these theoretical advantages, approximately ideal crystals sometimes have distinguished properties of practical importance. For instance, the perfect metal lattice has maximum electric conductivity and the perfect diamond has maximum transparency and stability. However, there is no general rule according to which only ideal crystals have properties optimized to material needs. In contrast, artisans such as smiths and steel-makers have long benefited from, even optimized the manufacturing of, impurities and crystal defects to improve their products. Chemists, on the other hand, when synthesizing new materials for technical applications, have virtually always worked towards pure and ideal crystals and then checked for their suitable properties. The chemical approach thus follows the aesthetic

\footnotetext{
$7 \quad$ To be fair, Werner arrived at his theory of coordination polyhedra not only by aesthetic preference but actually performed comprehensive experimental studies on the numbers of substitution isomers, a standard procedure of classical organic chemistry (Werner 1913/1966).
} 
preference of the pure and ideal form. While that has proved successful in some cases, it completely ignores, and despises, the entire field of impure, disordered, and defect crystals for aesthetic reasons. However, since the 1970s, that field has been explored by the newly emerging discipline of materials science and engineering. In particular, nanostructured materials, with crystal defects and disorders in the nanometer range, are the most flourishing and promising field, because tailoring the defects has become a means of tailoring unprecedented properties. The example illustrates that aesthetic values can be deeply misleading to the extent that they make you blind for rich opportunities, which, in that case, were harvested by others who either ignored or embraced the opposite of the aesthetic values.

Another chemical field in which the aesthetics of symmetrical forms has played a dominant role is the synthesis of molecules in which carbon atoms bind to form regular polyhedra or Platonic bodies. Since carbon atoms usually bind with bond angles of $109^{\circ}$, such molecules require increasingly distorted bonds if one goes from octahedron to cube to tetrahedron. Therefore, such molecules are extremely unstable and difficult to make, which requires sophisticated synthetic strategies. Indeed, since the 1970s many research groups had worked for years, if not for decades, on the synthesis of regular carbon polyhedra. It was rather like a sports competition, in which the goal was aesthetically attractive but extremely difficult to achieve (Grahn 1981; de Meijere 1982; Hoffmann 1990; Hargittai 2000, pp. 419f). Apart from the aesthetic attraction, it is questionable if there were at the beginning any aims involved other than that achieving the synthetic target would require developing major improvements of the synthetic toolbox for the benefit of synthetic chemistry. Only later they discussed possible spin-offs, such as the use of these extremely unstable compounds as explosives or as cages for the inclusion of ions. The aesthetic fascination with regular carbon polyhedra even involved a broader public in 1985 when Harold Kroto, Robert Curl, and Richard Smalley incidentally made and discovered a soccer ball-like stable carbon structure, which they called Buckminster fullerene and for which they received the 1996 Nobel Prize in Chemistry. Although that opened up the field of fullerenes as a new class of carbon compounds, for which technological applications were soon desperately sought for, the original fascination was a purely aesthetic one.

Taken together, the three examples discussed above prove that the aesthetic preference of symmetry and pure forms can play mixed roles with regard to epistemic and utilitarian research values. It can provide a useful (first-order) guide, as with Werner's structural classification of transition metal complexes; it can be deeply misleading, as with the chemists' neglect of impure and defect crystals; and it can provide arbitrary orientation for research whose usefulness needs to be established only afterwards.

\section{Aesthetics of molecular representations}

Like in other fields of science, colorful images are nowadays omnipresent in chemistry both in research publications and in public presentations. Enabled by recently improved print and display technologies as well as a growing business of cover-design artists, these images help make a field more attractive to colleagues, students, and a general public and as such are tools of popularization. However, visual representations of molecules have also been very important in chemical research at least since the mid-19th century. Indeed chemists have developed their own sign languages which they use not only for presentations but also for their own research planning and contemplation (Hoffmann and Laszlo 1991). They have built their own molecular model sets or used stereo images for three-dimensional representations and eagerly embraced the latest innovations, including interactive Internet images and virtual reality sets for the visual understanding of molecular structures.

These visualizations are necessary tools in the research process, as they help formulate questions and find solutions. Thus, it is more than likely that their graphic styles and aesthetic elements have an important impact on chemical research directions, and that research is 
frequently stimulated by aesthetic experiences. While case studies are still rare in this area, chemists have frequently expressed ideas in that regard. There is at least one example illustrating that such aesthetic experiences can stimulate the development of an entirely new research field, here the fields of supramolecular chemistry and molecular nanotechnology (Schummer 2006b).

In addition to their fascination with symmetrical molecules (Sect. 3), chemists have been particularly enthralled since the early 1980s by molecules that "look" like ordinary objects (e.g., Vögtle 1989). Because molecules are invisible, indeed the result of a model approach that reasonably applies only to certain substance classes, it is rather a set of molecular images that have raised their fascination. These images are captivating because of their ambiguity. On the one hand, they refer to entities in the molecular world; on the other, they refer to objects of the ordinary world, like a basket with a handle, a wheel on an axis, or a two interlocked links of a chain. From a classical chemical point of view, these two worlds are quite disparate and disconnected from each other, because all the molecular properties that chemists are interested in are just missing in ordinary world objects and vice versa. However, owing to their ambiguity, the images connected these two worlds in a productive manner that stimulated the imagination of combining both worlds into one. One way to combine both worlds appeared in funny cartoons of little humans walking through and playing with molecules like ordinary objects. Another way was to reproduce by chemical means the ordinary world in miniature. Indeed, since the 1980s, chemists have imitated all kinds of ordinary world objects on the molecular level, from funny things like dogs and pigs to technological artifacts like gears, turnstiles, and elevators. They have developed a whole battery of molecular systems and devices with various mechanical and electrical functions, like molecular machines and circuits. The field thus inspired by the aesthetic phenomenon of ambiguous images came to be known as supramolecular chemistry and, more recently, as molecular nanotechnology (Balzani et al 2003).

Umberto Eco's semiotic theory of aesthetics (Eco 1962/1989) is a useful approach to understand the aesthetic inspiration that has triggered the historical development (for more detail, see Schummer 2006b). Faced with ambiguous signs, the interpreter is prompted to lower the tension of ambiguity by developing new, potentially reconciling interpretations and by contemplating and revising the form of the signs. Indeed supramolecular chemists have not only tried to solve the ambiguity by reproducing the ordinary world on the molecular level, they have also developed a new chemical language of technomorph signs which they frequently use in combination with classical structural formulas. In accordance with Eco's aesthetic theory, this creates a new productive tension that calls for reinterpretation and semiotic revision as a reiterative process, which chemists perform by exploring further parts of the ordinary world on the molecular level and adjusting their sign language. In Eco's theory, the process eventually reveals more about the interpreters and their imagination than about the original signs. Estimated from the specific areas of the ordinary world that chemists have selected to imitate on the molecular level, chemists revealed a deep fascination with mechanical and electrical engineering.

The aesthetic experiences that stimulated the emergence of supramolecular chemistry and molecular nanotechnology are difficult to grasp by classical aesthetics of beauty. Moreover, it is hard to identify the aesthetic values underlying the chemists' aesthetic fascination with certain molecular representations. The example thus illustrates that the field of aesthetics in science is much richer than a simple product-oriented aesthetics of beauty would suggest, that intermediate representations and their symbolic references play an important role, and that more sophisticated aesthetic theories, like Eco's, are able to explain important research dynamics, which would otherwise remain miraculous. 


\section{Aesthetic virtues of chemical experimentation}

Scientists frequently use aesthetic categories like beauty to denote the importance, historical significance, or model character of certain experiments, as in top ten lists of "the most beautiful experiments" (Freemantle 2003). In so doing, they make some kind of value judgments without expressing the specific kind of value they mean. In order to identify the aesthetic kernel of such statements it is useful to exclude first the non-aesthetic values that are frequently confused with beauty. If an experiment is valued only because it produced new knowledge or confirmed or refuted a theory, the underlying value is not of aesthetic but of epistemic nature. Likewise, historical significance or importance is clearly not an aesthetic but an instrumental value, because it values something only because it enabled something else, for instance the subsequent development or the present state of the art, which here alone is considered valuable in its own right. More generally, if an experiment is valued only because of its result, for instance the synthesis of an important substance or some economic improvement, it is not the experiment but the result that matters. This also includes all cases in which the experiment is ethically valued in a consequentialist sense, for instance if it helps avoid harm by providing useful insights or by replacing harmful procedures like animal experiments. If we thus exclude all epistemic, instrumental, and ethical values and focus on the experiment itself, any further evaluation is likely to be guided by aesthetic values.

It might be recalled that in the experimental sciences like chemistry, an experiment is not just a test for hypotheses as in mathematical physics, but also an explorative approach under controlled conditions that might be related to improving theoretical knowledge but is more frequently aimed at discovering new effects or phenomena, including new substances as in synthetic chemistry. In a recent book, Philip Ball has scrutinized historical experiments in chemistry for their aesthetic appreciation by the chemical community (Ball 2005, see also Schummer 2006c). He found ten aesthetic traits that apply both to particular experiments and to the particular attitude of the experimenters in performing these experiments. By analogy with virtue ethics, one can speak of experimental virtues that are valued for aesthetic rather than epistemological reasons. Ball's ten virtues and the experimenters who exemplified them are: exact quantification (Johan Baptista van Helmont); attention to details (Henry Cavendish); patience in the conduct of the experiment (Marie Curie); elegance in the design of the experiment (Ernest Rutherford); miniaturization and acceleration of the experiment (various nuclear chemistry groups); conceptual simplicity (Louis Pasteur); imagination that transcends common views (Stanley Miller); simple-minded and straightforward reasoning (Neil Bartlett); economy and avoidance of deviations (Robert B. Woodward, see also Woodward 1989); and conceptually straightforward design (Leo Paquette).

One might object that these experimental virtues are also valued for epistemological and instrumental reasons because they would enable experimental success. However, even if they enabled experimental success in the particular historical cases, on which later chemists might place their hopes, these virtues do not guarantee success. There is no logical relation between the virtues and experimental success. Even worse, some virtues seem to contradict each other, for instance, imagination that transcends common views and simple-minded and straightforward reasoning. Ball's analysis rather provides categories to describe different styles of experimentation that have been valued at different times by different communities or research groups. Such styles include, beyond the standard methodology of the discipline, particular ways to approach a problem, particular foci and care on certain aspects of experimentation, and particular ways of reasoning or designing. Beyond epistemic and instrumental values, experimental styles meet aesthetic preferences that might resonate with general aesthetic preferences of the corresponding socio-historical context.

Aesthetic values thus perform an intermediate function in chemical experimentation. On the one hand, they are believed to enable experimental success, which qualifies them for provisional instrumental or epistemic rather than for aesthetic values proper. On the other 
hand, because these beliefs have no methodological basis but rather refer to general aesthetic preferences, they provide aesthetic guidance of research. If such guidance is successful in the long run, the aesthetic values can be incorporated into the standard methodology of the discipline and thus become epistemic or instrumental values.

\section{Aesthetic values in mathematical modeling}

There is a long Platonic tradition in mathematics that considers mathematical simplicity an aesthetic value in its own right. Based on the metaphysical belief that nature has a simple mathematical structure, mathematical physicists have tried to combine aesthetics with epistemology in order to derive mathematical simplicity as an epistemological criterion in science. For instance, the Cambridge professor of mathematics Paul Dirac (1963) famously claimed that for a physical theory the mathematical beauty of its equations, here its algebraic symmetry, is more important than its accordance with experiments. Dirac's controversial claim reflects the particular epistemological tension between experimental and theoretical physics at the time. His allusion to beauty helped him devalue the epistemological standards of the experimental sciences in favor of the epistemological standards of his own field, where the claim became influential. However, apart from such epistemological struggles, there is also an aesthetic appreciation of certain mathematical structures in fields that use mathematical models in a more instrumentalist way, particularly in chemical engineering and physical chemistry, which are therefore much more interesting in the present context.

A major issue in chemical engineering is to develop mathematical models of industrial processes where standard physical approaches of analysis do not work for complexity reasons, for instance, the fluid flow or heat transfer through a complicated system that cannot fully be described in simple geometrical and physical terms or that requires too many parameters with too many functional dependencies. A standard modeling approach for such systems is dimensional analysis (van Brakel 2000). The art of dimensional analysis consists in combining all possible parameters into a few terms such that all units cancel. In addition, these terms, which are called dimensionless numbers, must have a physical meaning and be accessible by the measurement of the system elements - for many standard engineering problems the data are even catalogued. If the analysis is successful, the modeling problem wondrously reduces from sheer over-complexity to a simple equation with few retrievable parameters. This sudden mathematical simplicity frequently raises an aesthetic appreciation among engineers (see, for instance, Aris 1997), which is above the suspicion of blind Platonist metaphysics because the model must be feasible in industrial processes. However, as with all appreciations of mathematical simplicity, it would be wrong to say that the solution of the modeling problem is guided by aesthetic values, because reducing the mathematical complexity is actually the proper engineering goal. Instead, the aesthetic feeling arises only in addition to the satisfaction from solving the problem.

Apart from simplicity, there are other mathematical features that are aesthetically valued by chemists. In particular, formal analogies are prominent candidates. If the mathematical structure of one equation is analogous to the mathematical structure of another, this suggests that the two systems described by these equations are somehow related to each other. For instance, studying the phenomenon of osmosis of liquid solutions, Jacobus Henricus van 't Hoff (1852-1911) derived in 1887 an equation that was formally analogous to the ideal gas law and for which he eventually received the first Chemistry Nobel Prize in 1901. The formal analogy made a deep aesthetic impression on many chemists and does so still today (see, for instance, Root-Bernstein 2003, p. 36), because it connected two formerly disparate fields to each other. It suggested that solutions and gases behave in similar ways and thereby eventually opened up the entire field of thermodynamics of solutions. Besides being scientifically productive, such analogies seem to be aesthetically satisfying because they 
suggest an underlying holistic structure of nature in which, despite the analytical approach of science, everything is related to each other.

One of the most impressive examples in this regard are the reciprocal relations by Lars Onsager (1903-1976), for which he received the Chemistry Nobel Prize in 1966. It was long known that a pressure difference causes matter flow, that a temperature difference causes heat flow, and so on for each pair of thermodynamic forces and flows. Yet, studying such forces and flows in more detail, Onsager found that a pressure difference can also cause heat flow and that a temperature difference can cause matter flow, and so on for each combination of thermodynamic forces and flows. Moreover, for each combination the flows are equal, which is mathematically expressed by the numerical equality of the reciprocal coefficients or by the symmetry of the coefficient matrix. Although Onsager's relations meet the need for mathematical simplicity, they clearly oppose the idea that nature is simple, because any flow is now related to any force, albeit in a regular way. Thus, the aesthetic satisfaction rather arises from the fact that, contrary to previous analytical approaches, the reciprocal relations reveal a deeply holistic structure of nature.

In general, there seem to be two different sources of aesthetic appreciation in mathematical modeling. One arises from unexpected or surprising mathematical simplicity, which equally applies to the modeling of natural and engineering systems. Other than an inclination to over-simplification, aesthetic values here cannot provide any extra-guidance of research, because what is aesthetically valued is at the same time the sought-after solution of the research problem. The other source of aesthetic appreciation seems to be rooted in metaphysical views of nature. Whether mathematical simplicity or the holistic constitution of nature, such metaphysical preconceptions are likely to have an impact on the personal choice of those research fields which promise aesthetic satisfaction to the individual researcher. In particular, the appreciation of analogous and holistic structures seems to be epistemologically productive because the exploration of analogies frequently opens up new insights and research directions.

\section{Conclusion}

In science as well as in everyday life, the term "beauty" is frequently used as a proxy for values that cannot be clearly defined. In this paper I have tried to identify aesthetic appreciations of chemists by exclusion of appreciations that are based on epistemic, instrumental, or ethical values. Although the distinction is not always clear-cut, the results prove that there is ample space for aesthetic values in various areas of chemical research. Indeed aesthetic values have played important roles in attracting people to chemical laboratory work, developing new materials, selecting and designing synthetic targets on a theoretical level, interpreting molecular representations, performing chemical experiments, and developing mathematical models.

The impact of aesthetic values has not always been productive with regard to epistemic and utilitarian goals. Particularly the extreme fascination of chemists with symmetry and purity has led to a strong and persistent neglect of "dirty" and disordered materials, which the new discipline of materials science and engineering has harvested instead, with many surprising results of economic importance. In other fields, however, the aesthetic fascination can inspire entirely new and promising research fields, as it did in supramolecular chemistry. In chemical experimentation, where aesthetic values shape the particular styles of experimentation in the form of experimental virtues, aesthetics allows for an intermediate space for provisional and tentative methodological values. In all cases, whether productive or not, the aesthetic values of the individual researchers have been important research motivation and inspiration.

The result, that aesthetic values can be both guiding and misguiding with regard to epistemic and utilitarian aims, should not be surprising. For, if aesthetic values are different 
from epistemic and utilitarian ones, one should reasonably expect, as a rule, conflict of values in cases where they guide us into different directions. Such conflicts are known between any two kinds of different values, including between epistemic and utilitarian values, when, for instance, the search for accuracy is limited by the need for practically useful results. However, scientific research is rarely routine work that strictly follows given rules. From initial decisions on a research project to questions on how to approach or solve a particular problem, direct epistemic and utilitarian guidance is frequently lacking or might even point into opposite directions. In all those states of the research process there is room for aesthetic preferences as a source of inspiration. If that turns out well, the aesthetic guidance might in retrospect appear as the right intuition. If not, it was at least a reasonable attempt to start with, a useful, if not indispensable, heuristics. As scientific research is an ongoing exploration of the yet unknown, the trials and errors of one's aesthetic preferences within that room shapes one's personal style and intuition, which adds to the satisfaction of research.

Even though aesthetic values cannot be taken as guide towards epistemic or utilitarian ends, they play an important, probably even indispensable, role in scientific practice, both for the individual researcher and the scientific community. Being aware of their existence and understanding their impact, chemists can better take advantage of them without falling victim to their possible misguidance.

\section{References}

Aris R (1997) Reflections on Keats' equation. Chem Eng Sci 52 (15):2447-2455

Ball P (2001) Bright Earth: Art and the invention of color. Viking, London

Ball P (2005) Elegant Solutions: Ten Beautiful Experiments in Chemistry. Royal Society of Chemistry, Cambridge, UK

Balzani V, Credi A, Venturi M (2003) Molecular Devices and Machines: A Journey into the Nanoworld, Wiley-VCH, Weinheim

Barham L (2002) Systematic Pigment Use in the Middle Pleistocene of South-Central Africa. Current Anthropology 43(1):181-190

Berthelot M (1860) Chimie Organique Fondée sur la Synthèse, vol. 2. Mallet-Bachelier, Paris Curtin DW (ed): 1982, The Aesthetic Dimension of Science. Philosophical Library, New York de Meijere A (1982) Sport, Spiel, Spannung - die Chemie kleiner Ringe. Chem in unserer Zeit 16:13-22

Dirac P (1963) The evolution of the Physicist's Picture of Nature. Sci Am, 208 (May):45-53

Eco U (1962) Opera aperta. Bompiani (English trans: The Open Work. Hutchinson, 1989)

Fabbrizzi L (ed.) (2012) Beauty in Chemistry: Artistry in the Creation of New Molecules. Springer, Heidelberg

Freemantle M (2003) Chemistry at its most beautiful. Chem Eng News, 81(34):27-30

Glenz W (ed) (1985) Kunststoffe - ein Werkstoff macht Karriere. Hanser, München

Grahn W (1981) Platonische Kohlenwasserstoffe. Chemie in unserer Zeit, 15:52-61

Hargittai I (2000) Candid Science: Conversations with Famous Chemists. Imperial College Press, London

Hoffmann R (1990) Molecular Beauty. Journal of Aesthetics and Art Criticism, 48:191-204

Hoffmann R, Laszlo P (1991) Representation in Chemistry. Angew Chem Int Ed Engl 30:1-16 Ihde AJ (1964) The Development of Modern Chemistry, Harper \& Row, New York

Jakobs S (2006) "Selbst wenn ich Schiller sein könnte, wäre ich lieber Einstein": Naturwissenschaftler und ihre Wahrnehmung der "zwei Kulturen". Campus, Frankfurt

Knight D (2006) Popularizing Chemistry: Hands-on and Hands-off. Hyle: Int J Phil Chem 12:131-140

McAllister JW (1996) Beauty and Revolution in Science. Cornell University Press, Ithaca Mossman S (ed) (1997) Early plastics: Perspectives, 1850 - 1950. Leicester Univ. Press, London 
Multhauf RP (1966) The Origins of Chemistry. Oldbourne, London

Root-Bernstein R. (2003) Sensual Chemistry: Aesthetics as a Motivation for Research. Hyle: Int J Phil Chem 9:33-50.

Schummer J (1995) Ist die Chemie eine schöne Kunst? Ein Beitrag zum Verhältnis von Kunst und Wissenschaft. Zeitschrift für Ästhetik und Allgemeine Kunstwissenschaft, 40:145178

Schummer J (2002) The Impact of Instrumentation on Chemical Species Identity: From Chemical Substances to Molecular Species. In: Morris P (ed) From Classical to Modern Chemistry: The Instrumental Revolution. Royal Society of Chemistry, Cambridge, pp. 188-211

Schummer J (2003a) Aesthetics of Chemical Products: Materials, Molecules, and Molecular Models. Hyle: Int J Phil Chem 9:73-104

Schummer J (2003b) The Notion of Nature in Chemistry. Stud Hist Phil Sci, 34:705-736

Schummer J (2006a) Symmetrie und Schönheit in Kunst und Wissenschaft. In: Krohn W (ed) Ästhetik in der Wissenschaft, Meiner, Hamburg, pp. 59-78

Schummer J (2006b) Gestalt Switch in Molecular Image Perception: The Aesthetic Origin of Molecular Nanotechnology in Supramolecular Chemistry. Foundations of Chemistry 8:53-72

Schummer J (2006c) The End of Silent Rites. Book Review of Philip Ball: Elegant Solutions: Ten Beautiful Experiments in Chemistry. Hyle: Int J Phil Chem 12:157-159

Schummer J (2014) The Methodological Pluralism of Chemistry and Its Philosophical Implications. In: Scerri ER, McIntyre L. (eds) Philosophy of Chemistry: Growth of a New Discipline. Springer, Dordrecht, forthcoming

Schummer J, Bensaude-Vincent B, Van Tiggelen B (eds) (2007) The Public Image of Chemistry, World Scientific Publishing, Singapore et al

Schummer J, MacLennan B, Taylor N (2009) Aesthetic Values in Technology and Engineering Design. In: Meijers A (ed) Philosophy of Technology and Engineering Sciences (Handbook of the Philosophy of Science, Vol. 9). Elsevier, Amsterdam et al, pp. 1031-1068

Spector TI (ed) (2013) Arts and Atoms. Leonardo and MIT Press, Cambridge MA

Spector TI, Schummer J (eds) (2003) Aesthetics and Visualization in Chemistry. Special issue of Hyle: Int J Phil Chem 9 (1 \& 2):3-243

Tauber AI (ed) (1996) The Elusive Synthesis: Aesthetics and Science. Kluwer, Dordrecht van Brakel J (2000) Modeling in Chemical Engineering. Hyle: Int J Phil Chem 6:101-116

Vögtle F (1989) Reizvolle Moleküle in der Organischen Chemie. Teubner, Stuttgart (English trans: Fascinating Molecules in Organic Chemistry. Wiley, Chichester, 1992)

Wechsler J (ed) (1978) On Aesthetics in Science. MIT Press, Cambridge MA

Weibel P, Fruk L (eds) (2013) Molecular Aesthetics, MIT Press, Cambridge MA

Werner A (1913/1966) On the Constitution and Configuration of Higher-Order Compounds. In: Nobel Lectures, Chemistry 1901-1921, Elsevier, Amsterdam, pp. 256-269

Woodward CE (1989) Art and elegance in the synthesis of organic compounds: Robert Burns Woodward. In: Wallace DB, Gruber HE (eds) Creative people at work: twelve cognitive case studies, Oxford University Press, Oxford, pp. 227-253 